\title{
Estudos biográficos de formação e pesquisa: caminhos para elucidação da problemática de estudo
}

\author{
Jarles Lopes de Medeiros ${ }^{1}$
}

\begin{abstract}
Resumo
Este artigo apresenta os percursos de formação, profissão docente e de pesquisa acadêmica que exerceram influências na elucidação da problemática para uma pesquisa realizada para Dissertação de Mestrado. Durante a narrativa, destacam-se experiências do autor em diferentes âmbitos de sua vida, as quais foram decisivas para a construção de sua identidade docente e acadêmica. Percebe-se que o nosso presente não está dissociado do passado. Durante a construção de uma pesquisa acadêmica, torna-se fundamental rememorar experiências com o objeto de estudo, buscando ressignificações do mesmo. Os resultados destacam a importância do uso do procedimento autobiográfico em trabalhos de pesquisa que tenham a autobiografia como dispositivo teóricometodológico.
\end{abstract}

Palavras-chave: Experiência; Formação; Pesquisa.

Biographical studies of training and research: ways to elucidate the study problem

\section{Abstract}

This article presents the training courses, teaching profession and academic research that exerted influences in the elucidation of the problematic for a research carried out for Master Thesis. During the narrative, we highlight the author's experiences in different areas of his life, which were decisive for the construction of his academic and academic identity. It is perceived that our present is not dissociated from the past. During the construction of an academic research, it is fundamental to recall experiences with the object of study, seeking re-significances of the same. The results point to the need to use the autobiographical procedure during the research.

Keywords: Experience; Formation; Research.

\section{Introdução}

Ora, eu sei, e não farei nada para escondê-lo, que na realidade fui descobrindo aos poucos os princípios que guiavam minha prática, mesmo que no terreno da pesquisa Bourdieu (2005, p. 38)

Este trabalho apresenta uma reflexão entorno das influências que a autobiografia exerce na construção e condução de uma pesquisa acadêmica. Experiências vividas ao longo da trajetória do pesquisador (pessoal, escolar, de formação e profissional) acabam por repercutirem na forma como se concebe o objeto de estudo e análise. A óptica de pesquisa não é neutra, está alicerçada em crenças e conceitos angariados ao longo da vida (BOFF, 1997; MARTINELLI, 1994).

\footnotetext{
${ }^{1}$ Universidade Federal do Ceará (UFC), Fortaleza-CE, jarlelope@gmail.com

Periódico Horizontes - USF - Itatiba, SP - Brasil - e020028
} 
O presente estudo é fruto de uma pesquisa realizada para Dissertação de Mestrado.

A pesquisa investigou as concepções e as práticas pedagógicas materializadas no discurso docente de nove professores de Educação Básica da rede pública de ensino no Município de Fortaleza no que diz respeito às questões relativas à família e à sexualidade. Visou identificar tais posturas a partir da análise de seus discursos. O intuito foi construir um panorama sobre a temática partindo da fala dos próprios professores, sob uma abordagem foucaultiana (FOUCAULT, 2011 e 2014), uma vez que tais profissionais foram convidados a falarem de si, de suas práticas e concepções. A partir de uma análise discursiva, suas falas foram sistematizadas a fim de construir um corpo teórico que contribuísse para a efetivação das discussões relacionadas à sexualidade no campo educacional.

Ao buscar uma justificativa que alinhasse os objetivos de estudos às motivações pessoais que me impulsionasse à busca, quase incessante, de compreensão, deparei-me cercado por experiências de formação e pesquisa. Foi aí que percebi que o interesse em investigar os temas relacionados à sexualidade surgiu, de forma mais consistente, a partir de uma pesquisa realizada para a monografia de conclusão do Curso de Pedagogia. Nesta pesquisa, discuti a sexualidade em sua dimensão mais ampla, abordando aspectos sociais, antropológicos, políticos e educacionais, o que culminou numa pesquisa empírica em algumas escolas de Educação Básica da rede pública de ensino no Município de Fortaleza.

Juntando-se à necessidade de dar continuidade e aprofundar a temática dessa pesquisa anterior, em nível bem inicial pelas suas próprias exigências de atender ao âmbito da graduação, aliaram-se as minhas vivências pessoais com o tema na escola, em um primeiro momento como aluno e, posteriormente, como professor de Educação Básica da rede pública de ensino. Nos tempos de estudante, quando ainda era criança/adolescente, vivi, silenciosamente, os sabores e os dissabores de existir no contexto da sexualidade posta no cotidiano sem uma orientação consistente. Preconceitos, estigmas e repressão nortearam, durante muito tempo, a minha conduta. Senti a intolerância de uma sociedade que segue os estereótipos de um modelo heteronormativo, em que a escola (silenciando e compactuando) reforça o status quo ${ }^{2}$ da

\footnotetext{
2 O recurso da grafia em itálico de algumas palavras aparece ao longo texto quando há referências a palavras estrangeiras, informais, títulos e/ou expressões da oralidade.
} 
discriminação e da violência, ao mesmo tempo em que, segundo Bourdieu (2009), produz, mas também reproduz, práticas de exclusão.

Quanto mais investigava a minha aproximação pessoal com a temática, percebia-me imerso em experiências balizantes. Dessa forma, surgiu a necessidade de compreender a minha relação pessoal com o tema de estudo. Conhecer a nossa trajetória e reconhecer o que nos marca como pessoas e profissionais é essencial para trilhar um itinerário coerente com nossos princípios e identificar escolhas, crenças, valores e concepções enquanto sujeitos socialmente construídos. Os percursos de vida e formação estão entrelaçados, ligados a inúmeros fatores de ordem pessoal, social, acadêmica e profissional, dentre outros.

A partir das pesquisas e leituras realizadas durante a trajetória acadêmica, compreendi que as memórias possuem um aspecto individual e coletivo. O que antes considerava tão somente particular, relacionado apenas às minhas vivências, tratava-se de um fenômeno, também, coletivo. Mais especificamente em relação aos temas da sexualidade, pude compreender que se tratava de um fenômeno que permeia e escapa à esfera individual.

Durante o Curso de Mestrado cursei algumas disciplinas que tiveram influência direta no desenvolvimento da pesquisa para a Dissertação. Quando ingressei no programa, já havia delimitado o objeto de estudo. Porém, no decorrer do curso, tive acesso a teorias que ampliaram o horizonte de pesquisa, sendo possível utilizar metodologias e abordar questões até então não cogitadas.

No que diz respeito ao trajeto de pesquisa até a delimitação do objeto de estudo, o que engloba formação acadêmica, pessoal e profissional, foi durante a Disciplina de Estágio I que atentei para o fato de que seria fundamental rememorar as experiências vividas não só no âmbito acadêmico, mas, sobretudo, algumas memórias infantis, nos tempos de estudante de Educação Básica. Tive a oportunidade de acompanhar as aulas do componente curricular Autobiografia e Educação, do Curso de Pedagogia.

A partir de tal experiência, foi possível realizar um percurso autobiográfico, de reconhecimento de si e de minhas práticas e concepções que carrego enquanto estudante, profissional e pesquisador. Uma dimensão subjetiva perpassou a narrativa de tal trajetória. Como metodologia para revisitar o passado em busca de elementos que afirmassem o envolvimento com o tema, assim como a motivação para discuti-lo, utilizei o procedimento 
autobiográfico, numa tentativa de compreender o itinerário por meio de uma valorização do genealógico pessoal (LANI-BAYLE, 2008), tanto no âmbito pessoal quanto coletivo.

Boccega (1995) destaca a memória individual como um discurso histórico que busca compreender o passado como construtor do presente. Dessa forma, através do processo de rememoração de fatos e experiências vivenciadas anteriormente, foi possível compreender melhor as intenções de pesquisa, ressignificando memórias que, até então, permaneciam enclausuradas no meu íntimo. A partir de uma postura reflexiva em torno do passado, através do procedimento autobiográfico, foi possível recompor os elementos que alicerçavam a óptica investigativa. Este artigo tem como objetivo apresentar tal percurso.

\section{Memórias estudantis e a aurora investigativa}

As experiências pessoais como aluno de Educação Básica foram determinantes para a minha postura diante do tema de estudo. Nos tempos de escola, mais precisamente ao longo do Ensino Fundamental I, numa instituição particular no bairro em que morava, era um garoto muito tímido, de poucos colegas, não possuía amigos. No cotidiano escolar, um dos maiores desafios era interagir com as pessoas. Qualquer manifestação da oralidade se tornava um desafio, algo difícil e conflituoso, o que pode ser ilustrado durante o ritual da chamada, da frequência, situação essa que era torturante confirmar a minha presença ao dizer, em voz alta, presente, uma vez que esse era um dos poucos momentos em que eu tinha que falar diante dos colegas. Fui levado a conceber a escola apenas do ponto de vista cognitivo, ficando a interação social negligenciada.

O processo de formação e educação do ser humano é para além da instrução escolar, transborda o conhecimento sistematizado no qual a referida instituição se alicerça. Numa sala de aula se torna impossível separar a dimensão humana da cognição, aquela perpassando todo o processo educativo. Para uma educação do sujeito integral, levando em consideração sua subjetividade, é fundamental a superação da concepção do aluno apenas como sujeito que pensa.

Não gostava das ocasiões que envolviam interações entre colegas e professores. Considerava o momento da sala de aula, em que os professores repassavam o conteúdo e os alunos em silêncio os observavam, o mais aconchegante dentro da instituição, pois ficávamos

Periódico Horizontes - USF - Itatiba, SP - Brasil - e020028 
contidos e em silêncio, portanto, às vezes, as agressões eram evitadas. O recreio era uma tortura, cada minuto parecia eterno, considero que sobrevivia, em meio a esquivas, entre agressões verbais e físicas. Costumava ficar sozinho, observando as outras crianças brincarem. Não sentia vontade de participar, a minha maior preocupação era não ser percebido.

Hoje, enquanto professor licenciado em Pedagogia, formação esta que apresenta múltiplas possiblidades didático-teórico-metodológicas que subsidiam e ampliam a compreensão em torno do processo de ensino e aprendizagem infantil, analiso aquela situação, vivenciada nos tempos de escola, como a de um garoto que possuía dificuldades em se relacionar com os colegas e professores, tendo, por isso, problemas no âmbito cognitivo, mas também afetivo, uma vez que não conseguia consolidar as atividades escolares, pois, em alguns casos, a interação social era essencial.

Nesse sentido, de acordo com Dantas (1992), a aprendizagem, segundo a teoria walloniana, está vinculada às questões afetivas. O desenvolvimento infantil é concebido de forma integral, abrangendo dimensões afetivas, cognitivas e motoras. Assim, o desenvolvimento não pode se restringir apenas a uma dessas dimensões. A teoria de Wallon nos possibilita compreender as relações envoltas entre professores e alunos. O meio onde os estudantes estão inseridos, a escola, repercute diretamente em seus processos cognitivos, sociais e afetivos, os quais são intrínsecos.

Percebido em sua totalidade, o aluno que possui no ambiente escolar experiências negativas no âmbito da afetividade pode ter prejudicado o seu processo de ensino e aprendizagem, uma vez que, conforme os princípios wallonianos, não existe aprendizagem sem afetividade (DANTAS, 1992). Não caberia neste ensaio uma análise completa da teoria walloniana, tampouco seria esse o objetivo do mesmo. 0 intuito nesse breve percurso em seus estudos é destacar que a escola não me percebia de forma integral, pois as situações de isolamento social eram negligenciadas pelos professores e demais colegas, o que repercutia no processo educativo.

As aulas de Educação Física, por exemplo, também eram carregadas de sofrimento, uma vez que exigia uma maior interação e movimento corporal durante os jogos e brincadeiras. Sempre convencia os meus pais a conseguirem um documento junto ao médico que me dispensasse de tais aulas. 
Essa resistência e fobia em relação à interação escolar não foi uma escolha pessoal. Compreendo que se tratava de um mecanismo de defesa que desenvolvi para suportar a singularidade do cotidiano escolar que participei. Vivenciei um processo de exclusão e violência protagonizado pelos meus pares. No Ensino Fundamental I eu era um garoto retraído, poucas vezes conseguia interagir. Sentia-me confortável com a situação de isolamento. Considero que lidava com uma vida dupla: na escola era introspectivo, mas no pessoal, em casa e na rua, era o oposto. A partir do 4음 ano a calmaria e invisibilidade escolar foi cedendo lugar a um sentimento de tormento, onde a instituição passou a ser um lugar hostil.

Naquela série demorei a adquirir o livro de Estudos Sociais, o que me fazia faltar às aulas da disciplina, até mesmo as duas primeiras avaliações. A professora polivalente, que morava em uma rua por trás da casa onde eu residia, chamava-me apenas pelo número, embora conhecesse a minha família e a mim desde a mais tenra idade. Na semana seguinte à primeira avaliação, chamou-me, repentinamente, pelo número para que fosse até a frente da sala, diante de sua mesa. Falou que devido à falta no dia da prova faria uma arguição, uma prova oral.

Sentava na última cadeira da sala e, como já dito, era um tormento responder à chamada. O trajeto da minha cadeira até a mesa da professora foi interminável, ainda lembro a sensação dos colegas me olhando enquanto caminhava. Ela fez a primeira, a segunda e a terceira pergunta, e permaneci apático, calado, sem emoções. Sabia as respostas, mas estava bloqueado por uma força maior. Fiquei com nota zero!

Na segunda avaliação, no bimestre seguinte, faltei novamente. Dessa vez, a professora perguntou à sala, com o seu tom de voz que demonstrava impaciência, com as sobrancelhas franzidas: quem é o número vinte? Fui submetido a uma nova avaliação oral e adquiri outro zero na disciplina. Fiquei com muito medo dessa professora, e no decorrer do ano, mesmo quando a mesma demonstrava momentos de afetividade comigo, considerava que ela me odiava. Até hoje, 25 anos depois, quando a vejo sinto algo ruim, volto a ser criança, fico com medo.

Ela é uma senhora aposentada, não teve filhos e ainda possui certa relação com a minha família. Embora durante toda a infância, adolescência e fase adulta tenhamos morado no mesmo bairro, nunca trocamos uma palavra além da relação professor e aluno. Às vezes, penso em ter uma conversa com ela relatando essas vivências. Fiquei estigmatizado pelos colegas como alguém que possuía duas notas zero, na 4ạ série. No mundo infantil isso era um verdadeiro 
escândalo. Acho que foi nesse período que o processo de exclusão se intensificou.

A relação professor-aluno vai além da questão pedagógica. Por mais que se tenha uma resistência por parte dos professores em reconhecer a importância dessa afetividade que permeia a prática docente, existem problemas em sala de aula que têm sua origem em questões afetivas. Portanto, é preciso uma postura sensível diante das problemáticas apresentadas pelos discentes.

Juntando-se àquele fato, principalmente, não me identificava com as brincadeiras masculinas, tampouco com as femininas. Não gostava e nem sabia jogar futebol e considerava tediosas as brincadeiras cor de rosa das meninas, por isso não participava dos jogos infantis escolares. Hoje percebo que essa apatia ao universo masculino borrou as fronteiras do gênero, do que é ser homem. Logo, os colegas perceberam na minha singularidade um motivo para a exclusão: a timidez foi confundida com algo feminino, tive a sexualidade contestada e fui rotulado de bicha, de gay. O estigma da homossexualidade me rondou nesse período, provocando violência física e simbólica.

Durante os dois anos seguintes (50 e 60 séries do Ensino Fundamental II) vivenciei um violento processo de exclusão, difamação e agressão física. Todos os dias, na sala de aula e no pátio, sempre havia alguém a me chamar por nomes femininos, personagens de novelas ou simplesmente de viado. Com o tempo, as agressões físicas e psicológicas em forma de brincadeiras se intensificaram. Chegou a um ponto em que naturalizei a questão, e era na invisibilidade que encontrava segurança. Ser considerado a bicha da escola não foi tarefa fácil, sentia muita vergonha e medo, não tinha voz para contestar. Meus dois irmãos estudavam na mesma instituição. O mais velho, quando tinha conhecimento de algum desses fatos, tentava intervir junto aos agressores. Por ter mais idade, ele possuía certo respeito e amenizava a situação momentaneamente. Mas quando não estava por perto, a situação parecia piorar.

Tudo acontecia diante de todos, alunos e professores, mas o silêncio e a negligência eram os caminhos escolhidos por tais profissionais, postura essa ainda muito presente na atual escola, onde os conflitos que envolvem as diversidades sexuais, relações de gênero, étnica, religiosa e cultural ainda são negligenciados, concebidos, muitas vezes, como brincadeiras. Sempre questiono os professores que dizem não haver conflitos dessa natureza na escola, principalmente quando os mesmos reconhecem que existem apenas brincadeiras inofensivas. 
Em muitas situações que a atual escola apresenta percebo elementos vivenciados por mim no passado: o comportamento esperado a partir do estereótipo de gênero e o silenciamento dos profissionais diante do conflito.

A escola se apresentava como um território árido, o qual perdia o sentido para mim. Faltava a muitas aulas com medo e vergonha. Sentia-me culpado por não me encaixar dentro de um padrão, o heteronormativo, no qual meninos e meninas deveriam assumir papéis bem distintos. Internamente, a questão não era a minha orientação sexual, não havia conflitos deste tipo, tampouco pensava sobre o assunto. E sim a expectativa social, o que aquela comunidade escolar pensava e falava ao meu respeito.

Essa trama culminou numa reprovação escolar. Na 6a série não consegui passar de ano. Com isso, mudei de escola e pude reconstruir uma nova vida, outra reputação. Durante aquele período, nenhum professor interviera nas sessões de agressão e, quando o faziam, era apenas para pausar o evento, nunca para discuti-lo. Esse acontecimento foi compreendido tempos depois, já na fase adulta, durante os percursos acadêmicos, momento em que pude compreender que a reprovação não se tratou de incompetência, como todos, até mesmo eu, pensavam.

A minha afetividade e subjetividade não estavam dissociadas da cognição. Como desenvolver o intelecto se o ambiente para isso se apresentada de forma árida? Concordo com Dantas (apud CERISARA, 1997) que afetividade e cognição são intrínsecas, a primeira estando na base dos primeiros anos de vida, guiando a razão. Recorrendo a Wallon, Lustosa (2009) compreende que o processo de construção de nossa identidade se dá partir do confronto/interação com o outro.

O recurso biográfico nos permite rememorar o passado em busca de elucidações do presente. Conforme Dominicé (2010), ao traçarmos fatos e percursos do nosso passado, despertamos a consciência do que somos, com reflexões sobre a nossa vida a partir de uma narrativa verídica, muitas vezes concebida, até então, como algo pessoal, mas que também diz respeito ao coletivo.

Fruto do nosso trajeto enquanto sujeitos acumuladores de experiências, o material biográfico, por meio da análise, gera conhecimento. Dominicé destaca a importância de se ir além do relato dos fatos, numa narração linear. O recurso biográfico deve permitir, a partir da 
análise e da reflexão, respostas às hipóteses suscitadas, lançando pistas que podem permitir a compreensão de fatos do presente. Assim, a narrativa apresentada neste ensaio elenca experiências que fazem parte do alicerce que constitui a minha identidade, a forma de ser e interagir com os outros, o que está intrínseco às abordagens e às problemáticas de pesquisa que desenvolvi ao longo da jornada acadêmica.

Não considero que tenha traumas psicológicos a ponto de ter sido impedido de realizar atividades futuras ou de criar laços afetivos com as pessoas. Dentre os inúmeros eventos que o sujeito vivencia ao longo da vida, aquele foi apenas mais um, que de alguma forma foi acomodado e canalizado para algo positivo, porém sempre se encontrando em um processo inacabado de compreensão. Quando mudei de escola, aos poucos fui considerando que havia virado a página. Ser tratado com respeito, ter amigos e ser reconhecido pelos professores passou a ser algo novo e prazeroso. Em determinado momento, no final da adolescência e início da fase adulta, pensei que aquela experiência era algo que dizia respeito apenas à infância, mais especificamente ao ambiente escolar.

No entanto, o presente nunca está dissociado do passado. O nosso desenvolvimento não é fragmentado, tampouco se dá de forma linear. Fatos vivenciados na infância repercutem durante toda a vida. Não é possível separar o adulto da criança que ele foi um dia, e as memórias infantis podem permanecer ao longo da vida, influenciando condutas e decisões. Durante anos, até bem pouco tempo atrás, carregava a culpa pela possível covardia diante dos colegas. Um questionamento me perturbava: por que eu não reagia? Hoje, para além de conseguir respostas, através de narrativas biográficas como a apresentada aqui, busco as marcas que me ajudaram a me constituir como sujeito.

\section{Cominhos para compreensão do passado na Universidade}

O tempo passava, mas os fatos vivenciados na infância estavam sempre presentes. Fentress e Wickham (1992) apontam que as memórias, diferentemente do conhecimento objetivo que provém do meio externo, muitas vezes, escapam a nossa compreensão, apresentando-se de forma transitória, fazendo parte do que somos. Nesse sentido, destacam a capacidade de rememoração como um traço marcante durante a vida: 
Podemos distinguir-nos de um sapo por sermos capazes de conservar factos objectivos na nossa cabeça; mas dificilmente nos distinguimos por sermos capazes de recordar. Portanto, recordamos conhecimento, mas também recordamos sensações. A memória, com efeito, penetra em todos os aspectos da nossa vida mental, dos mais abstractos e cognitivos aos mais físicos e inconscientes (FENTRESS; WICKHAM, 1992, p. 17).

Após ingressar na Universidade e ter acesso a algumas teorias a respeito dos fenômenos sociais que se processam dentro e fora da escola, movido pelas experiências pessoais, aproximeime das discussões relacionadas à prática do bullying. De acordo com Silva (2010), o termo só começou a ser discutido cientificamente a partir dos anos 1980 nos Estados Unidos. No Brasil, o debate emergiu nos círculos educacionais e psicológicos na década de 2000.

Porém, muito antes dessas discussões tomarem conta do discurso oficial na educação, psicologia e sociologia, a prática do bullying já vinha acontecendo, só não possuía uma nomenclatura, tampouco uma discussão sistemática consistente, por se tratar de um tipo de violência específica, no cotidiano escolar, movida principalmente por preconceitos. A escola visa à padronização dos indivíduos, que por meio de ritos e símbolos perpetua a concepção do sujeito ideal, contido, asséptico, rigidamente enquadrado em normas de gênero, interdito e silenciado dentro de sua sexualidade.

Existe uma banalização a respeito do tema, uma simplificação que acaba por naturalizar a prática. Sofrer bullying nos dias atuais se transformou numa espécie de gíria, onde qualquer rejeição ou brincadeira de cunho ofensivo passa a ser confundido com esse fenômeno. Beane (2010) apresenta uma discussão diante do tema e adverte que nem todo conflito vivenciado entre crianças e adolescentes fere o sujeito. Uma das principais características está relacionada à intenção de ferir e prejudicar, sendo exercido por práticas corriqueiras de violência que causam profundos problemas em diversos âmbitos da vida do indivíduo, sobre o corpo, o psicológico, o social, etc.

No início da graduação, no Curso de Pedagogia, elaborei um projeto de pesquisa visando ao desenvolvimento de uma monografia sobre o tema. Devido às experiências citadas anteriormente, as discussões em torno da prática do bullying despertaram o meu interesse, tornando-se objeto do referido estudo. Pude me reconhecer e compreender o processo de exclusão e violência vivenciado nos tempos de escola. De certa forma, perdoei-me pela possível 
covardia que acreditava possuir.

Contudo, durante a produção do estado da arte sobre o tema e das leituras para cerceamento do corpus teórico para as pesquisas, sentia-me insatisfeito. A literatura que dispunha na época, de uma forma geral, abordava apenas os sintomas do fenômeno, limitandose a descrever o perfil das vítimas e dos agressores, não se discutindo o pano de fundo: a intolerância e o preconceito. Sentia-me repetitivo ao discutir a temática.

$\mathrm{Na}$ época do desenvolvimento daquele projeto, não possuía um orientador fixo, e sim alguns professores que exerciam tal função. Para o desenvolvimento de Projetos de Pesquisa, os alunos do Curso de Pedagogia cursavam o componente curricular Estudos Orientados, divididos em 8 módulos, sendo necessário cursar um a cada semestre, culminando no componente curricular Monografia ao final do Curso. A cada semestre, um novo professor me orientava, sempre de forma superficial, uma vez que eles não acompanhavam a evolução das discussões, tampouco o meu envolvimento com o tema de estudo. Isso fazia com que não existisse um avanço qualitativo na problemática da questão.

Foi quando me aproximei de uma professora que viria a ser a minha orientadora até o final do curso. Relatei a minha angústia diante das pesquisas, que não conseguia avançar. Ela se disponibilizou para me orientar. A primeira observação realizada foi que eu deveria me dedicar às discussões relacionadas às motivações do preconceito, da violência e da exclusão, o que acaba por desaguar na prática do bullying.

As discussões em torno da prática do bullying não satisfaziam a minha necessidade de compreensão. Foi quando percebi que se tratava de um fenômeno bem mais amplo e antigo do que esse termo: o estigma. Para Goffman (2008), o estigma se relaciona com os desvios sociais. Alguns grupos, como no caso das pessoas Gays, Lésbicas, Bissexuais e Transgêneros (LGBTs), encontram-se à margem da sociedade, uma vez que não são aceitos pelos demais, tendo suas existências permeadas pela violência e exclusão. Os que não se enquadrarem no padrão tido como ideal, no caso a heterossexualidade, serão excluídos. A escola entende bem disso.

Percebi que deveria me dedicar às pesquisas voltadas para o cerne da questão vivenciada na vida escolar: o preconceito em torno das manifestações da sexualidade, dos estereótipos de gênero e a homofobia, uma vez que foram questões relacionadas a tais temas que motivaram as agressões físicas e psicológicas. 
Logo compreendi que discutir o preconceito sob a óptica da sexualidade não se relacionava apenas com os aspectos da prática sexual. O tema se relaciona com o ethos, com o comportamento humano. Pesquisar a sexualidade desencadeia uma vasta lista de assuntos acorridos dentro da escola e na sociedade: as concepções de família e infância, os estereótipos de gênero, o preconceito contra as diversidades sexuais, a questão religiosa, etc. Uma compreensão histórica e social do tema fez surgir inúmeras possibilidades de pesquisa.

A problemática da sexualidade não é algo recente. Foucault (2011 e 2014) foi um dos principais autores que influenciaram as referidas pesquisas e aborda o tema em diferentes momentos históricos, despertando a reflexão em torno da questão das relações de poder que permeiam o sexo e a sexualidade. Apresenta a sexualidade como um dispositivo histórico, suscetível de variações, dependendo do espaço e do tempo, refletindo normas e valores. Desde os tempos mais antigos, a questão se apresenta envolta de enigmas, preconceitos e incompreensão, sendo permeada por questões de poder. Pode-se dizer que estudar a sexualidade é, em última instância, um estudo sobre o poder.

A experiência de pesquisa na graduação propiciou um alicerce teórico que balizou pesquisas posteriores de mestrado e doutorado. Nesse sentido, o estudo realizado para a Dissertação de Mestrado considerou que tudo o que é social se relacionada com a sexualidade: as relações de gênero, as múltiplas configurações familiares, as diversidades sexuais, as DSTs, gravidez, identidade, traumas, relações sociais e trabalhistas, cognição, afetividade, violência, etc. Poderia listar aqui inúmeras ramificações que estão ligadas na teia da sexualidade. Além da relação com o social, o tema tem uma interface com o campo educacional, uma vez que tudo que diz respeito ao ser humano é de interesse da educação.

\section{Experiências profissionais}

Como pesquisador, tenho vivências e concepções pessoais que se relacionam diretamente como o tema de estudo, o que nos remete às palavras de Minayo:

[...] nas ciências sociais existe uma identidade entre sujeito e objeto. A pesquisa nessa área lida com seres humanos que, por razões culturais, de classe, de faixa etária, ou por qualquer outro motivo, tem substrato comum de identidade com 
o investigador, tornando-os solidariamente imbricados e comprometidos (apud LUSTOSA, 2003, p. 14).

Quando me iniciei na docência, no sistema de Educação Básica na rede pública de ensino, percebi que a minha prática não era neutra. As experiências nos tempos de escola, bem como o percurso formativo inicial, exerciam profunda influência na forma de conduzir o trabalho. No início, encontrei inúmeras dificuldades e lacunas formativas que me limitavam no enfrentamento das situações didáticas e sociais comuns em qualquer sala de aula. Com o tempo, percebi que a formação inicial que tivera não daria conta da complexidade que é estar como professor dentro de uma escola pública. Outro fato que se evidenciou foi que as experiências pessoais como aluno da escola no passado influenciavam diretamente a postura enquanto professor.

Nesse sentido, Tardif (2014) apresenta uma discussão em torno da epistemologia dos saberes docentes. Os saberes profissionais possuem uma fonte plural, não sendo possível creditar somente à graduação do professor toda a responsabilidade teórica e prática que o cotidiano docente exige. A graduação é apenas a formação inicial, à qual o profissional em formação tem acesso às inúmeras teorias que permeiam o universo educativo e social que encontrará posteriormente no exercício da profissão. O autor destaca outros saberes que incidem na formação docente: os saberes biográficos, oriundos da experiência de vida, seja na escola enquanto aluno, seja como professor; os saberes experienciais, os quais se formam no cotidiano da profissão; e o saber enciclopédico, oriundo dos livros didáticos. O importante a considerar é que na construção de uma identidade docente, mas também de pesquisa, não existe hierarquia entre tais sabres, tratando-se de um continuum.

Assim, enquanto professor de Educação Básica, percebo que, independentemente de políticas públicas impostas na escola para se abordar a sexualidade, o que realmente faz a diferença, numa contribuição qualitativa rumo à diversidade e à compreensão, sem estereótipos, são as posturas dos professores ao abordarem o tema, ao intervirem em conflitos que envolvam questões machistas e/ou preconceituosas. Pequenas atitudes diárias fazem a diferença. No entanto, ao invés disso, muitos professores silenciam e ficam de braços cruzados à espera de uma intervenção exterior.

Faz-se necessário refletirmos acerca do que é mais importante na constituição da Periódico Horizontes - USF - Itatiba, SP - Brasil - e020028 
identidade do sujeito. Quais seriam os elementos fundantes? Certamente existem múltiplos pontos que caracterizam tal processo, dentre eles a sexualidade. Alguns professores justificam a não abordagem do tema sexualidade na escola devido ao pouco tempo que dispõem para tratarem dos conteúdos curriculares. Não obstante, outros reservam, quase que diariamente, um tempo destinado às questões morais, visando ao bom comportamento dos alunos. De uma forma geral, eles têm a compreensão de que a escola não é só cognição, que existem outras manifestações do sujeito que incidem no processo educativo, não sendo possível, para o seu bom desenvolvimento, ignorá-las.

Por esses motivos, não foi difícil ouvir, ao longo das sessões de entrevistas realizadas para pesquisa de Dissertação do Mestrado, os docentes relatando suas angústias diante das posturas dos alunos, reclamando a não participação da família no processo educativo e que muitos buscavam formas de conscientização dos alunos por meio da Palavra de Deus, seja durante uma conversa no início da aula sobre ética e moral, seja sob o enfoque religioso. Independente da abordagem, a questão do comportamento desejável do ponto de vista escolar não era negligenciada. Porém, o mesmo esforço não foi percebido quando se referíamos à sexualidade, situações em que um silêncio esquivador se sobrepunha às tentativas de argumento para falar sobre o assunto em sala de aula.

Como todo espaço que envolve seres humanos, o grupo dos professores entrevistados não foi homogêneo no modo de pensar. Enquanto houve alguns menos abertos ao debate, outros possuíam uma concepção em harmonia com os princípios de uma sexualidade dialogável.

A relevância da pesquisa realizada se efetiva, uma vez que vivemos em uma sociedade sexualizada, onde existem apelos por todas as partes (nas ruas, na mídia, nas rodas de conversas, nas relações interpessoais, na escola, etc.), existindo um cultivo à violência e à intolerância. A sexualidade é debatida em espaços midiáticos, muitas vezes, sob o enfoque econômico sem a supervisão de um responsável. Os professores têm essa consciência, considerando que a sexualidade está presente em múltiplos espaços, sendo influenciada de várias maneiras.

Em pleno século XXI, ainda assistimos a algumas mazelas do passado assolando a sexualidade dos sujeitos: gravidez não planejada e cada vez mais precoce; índices crescentes de AIDS e demais DSTs; a insistência e a persistência sempre presente do machismo e da homofobia; a incompreensão diante dos diversos arranjos familiares; dentre outros. Com isso, acaba-se por 
naturalizar tais fatos. Ao mesmo tempo em que há o estímulo à prática sexual, à cópula e ao machismo, não se discutem tais questões, ficando tudo no âmbito do subentendido, à mercê dos apelos sexuais movidos pela mídia e orientados por princípios consumistas que banalizam o corpo e a mente das pessoas.

\section{Considerações finais}

O intuito da discussão apresentada em torno dos percursos autobiográficos envolvendo experiências pessoais com a escola e com a formação acadêmica e profissional é destacar a relação intrínseca que os temas sexualidade e educação possuem na minha trajetória de pesquisa e como o trabalho de rememoração das experiências contribuiu para elucidar as problemáticas suscitas em diferentes momentos do estudo. Nem sempre é fácil ou confortável falar de si, principalmente no desenvolvimento de um trabalho acadêmico. Ao longo do trajeto se torna impossível dissociar a fase da infância na escola da fase adulta na academia. Tampouco posso me desvincular dessas duas dimensões quando estou exercendo a profissão na instituição escolar. Assim, tais experiências integram um continuum.

Por meio de uma espécie de viagem ao passado busco me compreender e encontrar esse professor que atua no pátio da escola e nos espaços acadêmicos desenvolvendo pesquisas que visam à compreensão do seu ambiente de trabalho. O professor pedagogo lida com inúmeras infâncias em sua prática. Por esse motivo, é fundamental que o mesmo tenha em mente o significado e as particularidades dessa fase do desenvolvimento humano. O percurso autobiográfico certamente subsidia esse profissional no enfrentamento dos desafios da prática educativa. Concordando com Lustosa (2003), compreendo hoje que um objeto de investigação se dá por meio de relações múltiplas entre sujeito e objeto de investigação "[...] resultando das 'oportunidades' que a vida e as relações com o mundo social possibilitaram. Essas implicações incorporam diferentes dimensões [...] desde a escolha dos sujeitos até as opções teóricometodológicas" (p.11).

O caminhar biográfico não está dissociado dos aspectos psicológicos. A subjetividade foi determinante na construção desta narrativa. Ao longo do nosso desenvolvimento físico e psicológico vivenciamos inúmeras fases no decorrer da vida. Temos fatos guardados em nossa 
memória que nos permitem fazer uma arqueologia em torno de nossa existência, da infância, da adolescência, etc. No entanto, tal percurso não se dá de forma linear, e sim por marcos psicológicos a partir da interação com o meio.

A memória não possui fronteiras, ela permeia a vida dos sujeitos, realizando um movimento complexo de ida e volta. Nesse sentido, Freud (1974) anuncia que existe uma grande dificuldade em preservarmos as etapas do nosso desenvolvimento de forma sequencial. As fases do desenvolvimento infantil vão sendo substituídas pelas seguintes, ao ponto que em determinado momento de nossas vidas nos tornamos irreconhecíveis para nós mesmos, onde nem de longe lembramos a criança que fomos, apesar da estrutura psíquica e suas memórias permanecerem preservadas.

De acordo com o psicanalista, as fases precedentes fornecem subsídios para as posteriores, onde aquela não permanece intacta. Somos seres em constante mutação. Apenas a mente humana consegue preservar ao longo do tempo as etapas vivenciadas, que acabam por determinar o nosso comportamento, a nossa Psique. O sujeito que hoje desenvolve pesquisas como as relatadas, dentre outras, de alguma forma está ligado àquela criança tímida a qual considera que vivenciou um processo de exclusão no ambiente escolar.

A ex-professora do 4을 ano, que despertava em mim um sentimento estigmatizante, vez ou outra, materializa-se, aos meus olhos, na personalidade de alguns professores com os quais convivo no ambiente escolar e na Universidade. Isso talvez justifique certa cautela ao lidar com os mesmos atualmente, e perfil do qual busco me afastar quando na organização da minha prática pedagógica, sempre em construção.

Por outro lado, o espírito dos colegas que me agrediam no início dos anos 1990, de alguma forma ronda qualquer ambiente novo ou desconhecido. Dissociar esses fatos, levando em consideração o passar de duas décadas, como se fosse possível compartimentalizar épocas que se sucedem e que não se conectam, isentaria os referidos trabalhos de pesquisa de subjetividade, deixando o pesquisador autoral escondido e silenciado pelos autores considerados de referência.

Embora existam inúmeros subsídios teóricos que se tornaram fundamentais para a execução dos estudos passados e futuros, e sem os quais eu não teria desenvolvido uma compreensão do tema proposto em perspectiva mais ampla, para além do meio que me 
circunda, considero que o mais importante não seja o que dizem os autores, mas no que suas teorizações nos ajudam a compreender melhor o fenômeno e sua circunscrição no tempo presente, notadamente, nas interações no âmbito do espaço educativo e formativo dos sujeitos, no contexto escolar.

Essa afirmação, em nenhuma hipótese, tem o intuito de desqualificar o estudo teórico. Como já afirmei, o mesmo foi e continua sendo essencial para a elucidação da problemática, para o garimpar metodológico, além de ter me ajudado a compreender que as minhas experiências que por tanto tempo permaneceram enclausuradas no meu âmbito privado dizem respeito, também, ao coletivo (HALBWACHS, 2006). O que somos hoje, o que defendemos, está relacionado ao nosso passado, portanto, traz à tona nosso percurso.

Em determinados momentos, essa liberdade subjetiva na condução da narrativa pode ter gerado crises de inconsistência teórica, uma vez que não somos formados para falar livremente sobre qualquer assunto na academia, sendo necessário o caminhar junto com os autores. No entanto, acredito ser possível transitar entre o íntimo, o teórico e o coletivo, sendo a relação entre essas três dimensões o que dá sentido ao trabalho acadêmico. Dessa forma, concluo este recorte da pesquisa, no qual mais explicitamente pela via subjetiva apresentei a escolha e a construção do objeto de estudo, reafirmando Freud (1974) quando assinala que o nosso passado se encontra preservado na nossa vida mental, portanto não podemos desconsiderá-lo.

\section{Referências}

BEANE, Allan L. Proteja seu filho do bullying. Tradução: Débora Guimarães Isidoro. Rio de Janeiro: BestSeller, 2010.

BOCCEGA, Maria Aparecida. Palavra e discurso: História e Literatura. Inserir edição. São Paulo: Ática, 1995.

BOFF, Lonardo. A águia e a galinha. Uma metáfora da condição humana. 22a .ed. Petrópolis/RJ: Vozes, 1997.

BOURDIEU, Pierre. Esboço de auto-análise. Inserir edição. São Paulo: Companhia das Letras, 2005.

BOURDIEU, Pierre. A reprodução: elementos para uma teoria do sistema de ensino. Inserir 
edição. Rio de Janeiro: Vozes, 2009.

CERISARA, Ana Beatriz. A psicogenética de Wallon e a educação infantil. Perspectiva. Florianópolis, v. 15, no 28, p. 35-50, jul/dez, 1997.

DANTAS, Heloysa. Afetividade e a construção do sujeito na psicogenética de Wallon. In: LA TAILLE, Yves; Dantas, Heloysa; Oliveira, Marta Kohl. Piaget, Vygotsky e Wallon: teorias psicogenéticas em discussão. São Paulo: Summus Editorial, 1992.

DOMINICÉ, Pierre. O processo de formação e alguns dos seus componentes relacionais. In: NÓVOA, Antonio; FINGER, Mathias. O método (auto) biográfico e formação. São Paulo: Paulus, 2010.

FENTRESS, James; WICKHAM, Chris. Memória social: novas perspectivas sobre o passado. Lisboa: Editorial Teorema, LDA, 1992.

FOUCAULT, Michel. História da sexualidade I: a vontade de saber. 21a ed. Rio de Janeiro: Graal, 2011.

FOUCAULT, Michel. A ordem do discurso: aula inaugural no Collège de France, pronunciada em 2 de dezembro de 1970/Michel Foucault. Tradução Laura Fraga de Almeida Sampaio. 24a Ed. São Paulo: Edições Loyola, 2014.

FREUD, Sigmund. O mal-estar na civilização. In: . O futuro de uma ilusão, O mal-estar da civilização e outros trabalhos (1927-1931). Edição Standard Brasileira das Obras Psicológicas Completas de Sigmund Freud. Vol. XXI. Rio de Janeiro: Imago, 1974.

GOFFMAN, Erving. Estigma: notas sobre a manipulação da identidade deteriorada. Rio de Janeiro: LTC, 2008.

HALBWACHS, Maurice. Memória coletiva. Inserir edição. São Paulo: Centauro, 2006.

LANI-BAYLE, Martine. Histórias de vida: transmissão intergeracional e formação. In: PASSEGGI, Maria da Conceição (org.). Tendências da pesquisa (auto)biográfica. Coleção (Auto)Biografia/Educação. Natal: EDUFRN; São Paulo: Paulus, 2008.

LUSTOSA, Francisca Geny. Concepções de deficiência mental e prática pedagógica: contexto que nega e evidencia a diversidade. 2003. 260f. Dissertação (Mestrado em Educação Brasileira) - Universidade Federal do Ceará, Departamento de Educação, Fortaleza-CE, 2003.

LUSTOSA, Francisca Geny. Inclusão, o Olhar que Ensina: o Movimento da Mudança e a Transformação das Práticas Pedagógicas no Contexto da Mudança e a Transformação das Práticas Pedagógicas no Contexto de uma Pesquisa-Ação Colaborativa. 2009. 203f. Tese (Doutorado em Educação). Universidade Federal do Ceará, Fortaleza, 2009. 
MARTINELLI, Maria Lúcia. Uso de abordagens qualitativas na pesquisa em Serviço Social: um instigante desafio. Caderno do Núcleo de Estudos e Pesquisa sobre Identidade.São Paulo: PUCSP/Programa de Estudos Pós-Graduados em Serviço Social, n. 1, p.1-18, 1994.

SILVA, Ana Beatriz Barbosa. Bullying: mentes perigosas nas escolas. Inserir edição. Rio de Janeiro: Objetiva, 2010.

TARDIF, Maurice. Saberes docentes e formação profissional. 16ạ ed. Petrópolis, RJ: Vozes, 2014.

Recebido em agosto 2018.

Aprovado em março 2020. 